\title{
Optimal management strategies for primary headache in the emergency department
}

\author{
Simon Wells ${ }^{1} \cdot \operatorname{lan}$ G. Stiell ${ }^{1,4} \cdot$ Evgeniya Vishnyakova $^{2} \cdot{\text { Ronda } \text { Lun }^{3} \cdot \text { Marie-Joe Nemnom }}^{4} \cdot$ Jeffrey J. Perry ${ }^{1,4}(\mathbb{C}$
}

Received: 19 February 2021 / Accepted: 24 June 2021 / Published online: 14 August 2021

(C) The Author(s), under exclusive licence to Canadian Association of Emergency Physicians (CAEP)/ Association Canadienne de Médecine d'Urgence (ACMU) 2021

\begin{abstract}
Purpose We sought to evaluate the factors associated with better outcomes for emergency department (ED) patients treated for primary headache.

Methods This was a health records review of consecutive patients over a 3-month period presenting to two tertiary EDs and discharged with a diagnosis of primary headache. The primary outcome was the need for second round medications, defined as medications received $>1 \mathrm{~h}$ after the initial physician-ordered medications were administered. We performed multivariate logistic regression analysis to determine treatment factors associated with need for second round medications.

Results We included 553 patients, mean age was 42.2 years and $72.9 \%$ were females. The most common diagnoses were headache not otherwise specified (48.8\%) and migraine (43\%). Ketorolac IV (62.2\%) and metoclopramide IV (70.2\%) were the most frequently administered medications. $18 \%$ of patients met the primary outcome. Dopamine antagonists (OR 0.3 [95\% CI 0.1-0.5]) and non-steroidal anti-inflammatory drugs (NSAIDs) (OR 0.5 [95\% CI 0.3-0.8]) ordered with initial medications were associated with reduced need for second round medications. Intravenous fluid boluses $\geq 500 \mathrm{ml}$ (OR 2.8 [95\% CI: 1.5-5.2]) and non-dopamine antagonist antiemetics (OR 2.2 [95\% CI 1.2-4.2]) were associated with increased need. Opioid use approached statistical significance for receiving second round medication $(p=0.06)$.

Conclusion We determined that use of dopamine antagonists and NSAIDs were associated with a reduced need for second round medications in ED primary headache patients. Conversely, non-dopamine antagonist antiemetic medications and intravenous fluids were associated with a significantly increased need for second round medications. Careful choice of initial therapy may optimize management for these patients.
\end{abstract}

Keywords Headache $\cdot$ Migraine $\cdot$ Emergency department

\section{Résumé}

Objectif Nous avons cherché à évaluer les facteurs associés à de meilleurs résultats pour les patients des services d'urgence traités pour des céphalées primaires.

Méthodes Il s'agissait d'un examen des dossiers médicaux de patients consécutifs sur une période de 3 mois se présentant à deux services d'urgence tertiaires et sortis avec un diagnostic de céphalée primaire. Le résultat primaire était la nécessité d'une deuxième série de médicaments, définis comme des médicaments reçus $>1$ heure après l'administration des premiers

Jeffrey J. Perry

jperry@ohri.ca

1 Department of Emergency Medicine, Clinical Epidemiology Unit, The Ottawa Hospital, F647, 1053 Carling Avenue, Box 685, Ottawa, ON K1Y 4E9, Canada

2 University of Ottawa, Ottawa, ON, Canada

3 Division of Neurology, Department of Medicine, The Ottawa Hospital, Ottawa, ON, Canada

4 Clinical Epidemiology Program, Ottawa Hospital Research Institute, Ottawa, ON, Canada 
médicaments prescrits par le médecin. Nous avons effectué une analyse de régression logistique multivariée pour déterminer les facteurs de traitement associés au besoin de médicaments de second tour

Résultats Nous avons inclus 553 patients, l'âge moyen était de 42,2 ans et 72,9\% étaient des femmes. Les diagnostics les plus fréquents étaient les céphalées non spécifiées autrement (48,8\%) et la migraine (43\%). Le kétorolac IV (62,2\%) et le métoclopramide IV (70,2\%) étaient les médicaments les plus fréquemment administrés. $18 \%$ des patients ont atteint le résultat primaire. Les antagonistes de la dopamine (OR 0,3 [IC $95 \%$ : 0,1-0,5]) et les anti-inflammatoires non stéroïdiens (AINS) (OR 0,5 [IC $95 \%: 0,3-0,8]$ ) commandés avec les médicaments initiaux étaient associés à un besoin réduit de médicaments de deuxième série. Les bolus liquidiens intraveineux $\geq 500 \mathrm{ml}$ (OR 2,8 [IC $95 \%$ : 1,5-5,2]) et les antiémétiques non antagonistes de la dopamine (OR 2,2 [IC 95\% : 1,2-4,2]) étaient associés à un besoin accru. L'utilisation d'opioïdes a approché la signification statistique pour la réception d'un médicament de deuxième série $(\mathrm{p}=0,06)$.

Conclusion Nous avons déterminé que l'utilisation d'antagonistes de la dopamine et d'AINS était associée à un besoin réduit de médicaments de second tour chez les patients souffrant de céphalées primaires aux urgences. À l'inverse, les médicaments antiémétiques non antagonistes de la dopamine et les fluides intraveineux étaient associés à un besoin significativement accru de médicaments de second tour. Un choix judicieux du traitement initial peut optimiser la prise en charge de ces patients.

\section{Clinician's capsule}

\section{What is known about the topic?}

While primary benign headaches are commonly seen in the ED, there are no widely accepted treatment regimens.

\section{What did this study ask?}

What management patterns are associated with more effective and rapid resolution of symptoms for patients with primary headache in the ED

\section{What did this study find?}

Dopamine antagonists and NSAIDs reduced the need for second round medication whereas non-dopamine antagonist antiemetics and intravenous fluids were associated with treatment failure.

\section{Why does this study matter to clinicians?}

Careful choice of initial therapy may lead to more effective and rapid resolution of symptoms for ED patients with primary headache.

\section{Introduction}

\section{Background}

\section{Importance}

Recommendations have been published on the treatment of primary headaches in the ED [6,9-11], yet there is still significant variability in treatment recommendations [12, 13]. Generally, medications recommended for these patients include dopamine antagonists (e.g. prochlorperazine, metoclopramide), non-steroidal anti-inflammatory drugs (NSAIDs), serotonin receptor modulators (e.g. dihydroergotamine, triptans) and acetaminophen [6, 11, 14]. The literature suggests that parenteral opioids are overused [15-17], despite evidence demonstrating poorer outcomes with parenteral opioids including longer lengths of stay, less effective symptom relief, and higher rates of return visits [17-20]. Little is known about the current practice patterns of emergency physicians in treating primary headache and how the initial therapies being chosen by physicians influence outcomes.

\section{Goals of this investigation}

In this study we aimed to describe the primary headache population presenting to a tertiary care ED, as well as the practice patterns of ED physicians in treating primary headaches. We sought to determine which classes of medications and specific interventions were administered and what investigations were conducted for patients with primary headaches, with the primary objective of identifying management patterns associated with more effective and rapid resolution of symptoms for patients with primary headache in the ED. The primary outcome for our study was the need for a second round of medications.

\section{Methods}

\section{Design and setting}

This study was a health records review of consecutive adult patients who presented to the Ottawa Hospital EDs and were discharged with a diagnosis of primary headache over a 3-month period in 2018. The Ottawa Hospital is a tertiary care referral center with 2 EDs, 95 emergency medicine 
physicians and 55 residents that see a combined annual volume of 160,000 patients per year.

\section{Participants}

Eligible patients were identified searching the Ottawa Data Warehouse for ED patients $\geq 18$ years old with ICD-10 discharge diagnoses of a primary headache. The Ottawa Data Warehouse is a relational database containing information from the Ottawa Hospital's most important operational information systems, including patient registration system, clinical data repository, discharge abstracts, and personnel scheduling system. It includes data from 1996 to 2019. For this study, patients were eligible if they received medical treatment for their headache in the ED. As we aimed to evaluate treatment strategies for primary headache patients that led to discharge from the ED, we excluded patients who left without being seen by a physician, were transferred from another center for computed tomography (CT) imaging or assessment directly by a specialist, were admitted, were treated mainly for a condition other than primary headache, or had a principal diagnosis other than primary headache. We further excluded patients at increased risk for a secondary cause of headache (including those that were pregnant, had a Glasgow Coma Scale $(\mathrm{GCS})<15$, active cancer, head trauma within $24 \mathrm{~h}$, or stroke/neurosurgery within 3 months). Patients who presented within 7 days of their first visit for headache had their subsequent encounters noted but these follow-up encounters were excluded. This study was approved by the Ottawa Health Science Network Research Ethics Board.

\section{Measurements}

We collected demographics including age, sex, and presenting complaint. We recorded medications administered, intravenous (IV) fluids administered, neuroimaging studies performed, bloodwork investigations, lumbar punctures performed, pain reassessments documented on the chart, discharge diagnosis, prescriptions written, and follow-ups requested. Times of registration, physician assessment, first round medications, second round medications, and discharge were obtained. Data were extracted by two trained research assistants (SW, EV) using a standardized data collection form. $15 \%$ of charts were randomly assessed by the principal investigator (SW) for accuracy. No systematic errors were found. To ensure only primary headaches were included, all patients had their subsequent ED visits over a minimum 10-month period (up until the time of chart review) audited for secondary headache diagnoses. Data were entered in an Excel spreadsheet. There was no missing data for the primary outcome. Variables with significant missing data included triage pain scores and pain reassessments. Charts that were unable to be accessed were excluded.

\section{Outcomes}

Our primary outcome was the need for the administration of a second round of medications for headache treatment. First round medications were defined as the first physicianordered medication and all other medications administered within 1-h. Medications after this first hour were considered second round. We chose a 60-min cut-off to allow time for multiple medications to be given, as most physicians initially ordered multiple parenteral agents that were often infused over time with IV fluids. The secondary outcome was a long length of stay in the emergency department, defined as $>3.5 \mathrm{~h}$ from the time of initial physician assessment to discharge.

\section{Data analysis}

Descriptive statistics are presented as frequencies with proportions for categorical variables and means with standard deviations (SD) or medians with interquartile ranges (IQR), as appropriate. Associations between certain variables and the outcomes were assessed using chi-square test, t-test, or Wilcoxon test. A stepwise forward-selection multivariable logistic regression model was fit, with the following covariates included: arrival by ambulance, sex, prior visit to ED within 12 months, administration of triage medications by nursing, administration of first-round medications by medication class, administration of IV fluids, and investigations ordered for headache in the ED. Covariates chosen for inclusion in the model were based on possible confounding variables identified from our literature review, statistical significance based on our univariate analyses, and clinical judgement of the practicing emergency physician authors. Results are reported as odds ratios with $95 \%$ confidence intervals (CI). All statistical analyses were performed with SAS version 9.4 (SAS Institute Inc, Cary/NC).

\section{Results}

\section{Characteristics of study subjects}

We reviewed 1017 ED charts of consecutive patients diagnosed with primary headache from 1 June 2018 to 31 August 2018. Of these, 464 charts were excluded from analysis. The most common reason for exclusion was not receiving any medical treatment for headache (Fig. 1). Most patients who did not receive treatment were elderly, refused medication, or no longer had headache at the time of physician assessment. Overall, 553 charts were included. 
Fig. 1 Flow diagram for charts included in review

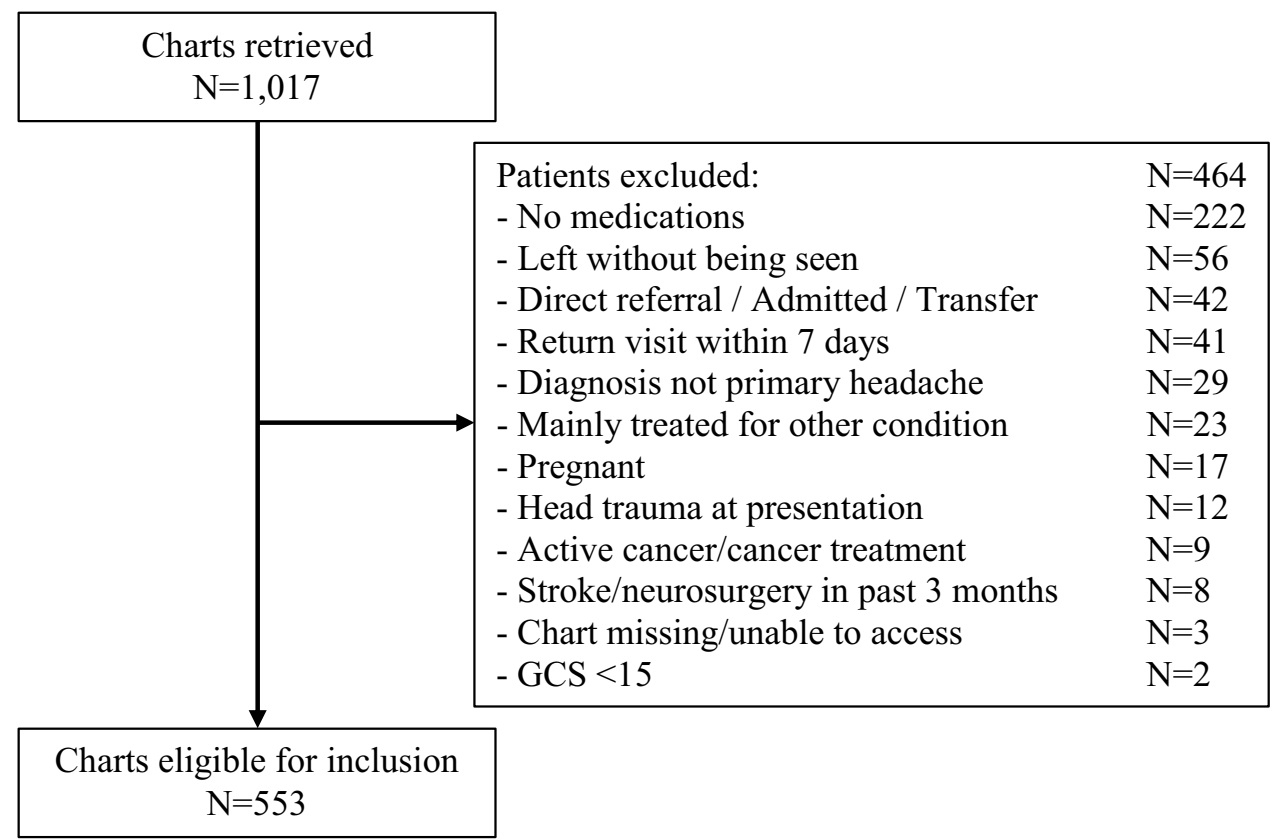

Table 1 outlines demographics, treatments, dispositions, and outcomes. The mean age of our cohort was 42.2 years and $72.9 \%$ of patients were female. Headache was the presenting complaint in $79.9 \%$ of patients. The most common diagnoses at discharge were headache not-otherwise-specified $(48.8 \%)$ and migraine (43.0\%). At triage, $19.0 \%$ of patients were given oral medications by nursing staff, most commonly acetaminophen $(15.7 \%)$. Among treatments after physician assessment, metoclopramide IV (70.2\%) and ketorolac IV (62.2\%) were the most frequently used. $11.6 \%$ of patients received an opioid medication. More than half $(53.2 \%)$ of patients had investigations done in the ED, including $35.3 \%$ undergoing CT head imaging and $35.8 \%$ having bloodwork. The mean total duration of ED stay was $5.0 \mathrm{~h}$ and the mean duration from initial physician assessment to discharge was $2.9 \mathrm{~h}$. Overall, 142 (25.7\%) patients had a prolonged stay $>3.5 \mathrm{~h}$ from initial physician assessment to discharge.

\section{Main results}

A total of $100(18.1 \%)$ patients met the primary outcome and received second round medications. Table 2 compares the univariate factors associated with requiring second round medications. Patients who did not require a second round of medications were more frequently administered NSAIDs (72.4 vs. $57.0 \%, p=0.002)$ and dopamine antagonists (70.9 vs. $51.0 \%, p<0.001)$ compared to those who required second round medications. There was a higher percentage of migraine patients among those requiring second round medications ( 53.0 vs. $40.8 \%, p=0.03$ ), whereas there was a lower percentage of patients classified with headache not-otherwise-specified (39.0 vs. $51.0 \%, p=0.03)$ that needed second round medication. Patients who required second round medications were more likely to have received opioids $(19.0 \%$ vs $6.4 \%, p<0.001)$, antiemetics (23.0 vs. $7.3 \%, p<0.001$ ), and acetaminophen (43.0 vs. $32.7 \%$, $p=0.01)$ compared to those that were successfully treated with the first round of medications. Patients who required second round medications were also more likely to have had ED investigations (64.0 vs. $50.8 \%, p=0.02$ ) compared to those who did not.

The multivariable logistic regression model (Table 3) found that first round NSAIDs (ketorolac, ibuprofen, naproxen) (OR 0.50, 95\% CI 0.30-0.83, $p=0.008$ ) and dopamine antagonists (metoclopramide, haloperidol) (OR $0.27,95 \%$ CI $0.14-0.49, p<0.001)$ were associated with decreased need for second round medications. Both IV fluids $\geq 500 \mathrm{ml}$ (OR 2.79, 95\% CI 1.50-5.19, $p<0.001)$ and first round non-dopamine antagonist antiemetics (dimenhydrinate, ondansetron) (OR 2.21, 95\% CI 1.15-4.24, $p=0.02$ ) were associated with increased need for second round medications. Opioid (hydromorphone, morphine, tramadol) use approached statistical significance for needing second round medications $(p=0.06)$. Given that dexamethasone is administered to prevent headache recurrence rather than headache resolution, it was not included as a covariate in the regression model, despite its significant association with a need for second round of medications (Table 2).

For the secondary outcome, patients who had shorter lengths of stay were younger (mean age 40.1 vs 48.1 , $p<0.001)$ and more likely to receive an NSAID in the first round of medications ( 72.3 vs. $62.0 \%, p=0.02$ ). Factors associated with prolonged length of stay included arrival 
Table 1 Breakdown of demographics, treatments, outcomes and disposition plans for 553 patients treated for primary headache

\begin{tabular}{|c|c|}
\hline Demographics & $N=553$ \\
\hline Age (years), mean (SD) & $42.2(16.6)$ \\
\hline Female, $n(\%)$ & $403(72.9)$ \\
\hline Arrival by ambulance, $n(\%)$ & $105(19.0)$ \\
\hline Canadian Triage Acuity Scale, median (IQR) & $3(2-3)$ \\
\hline Triage pain score recorded, $n(\%)$ & $288(52.1)$ \\
\hline Triage pain score, median (IQR) & $8(6-9)$ \\
\hline \multicolumn{2}{|l|}{ Presenting complaint to ED, $n(\%)$} \\
\hline Headache & $442(79.9)$ \\
\hline Dizziness & $24(4.3)$ \\
\hline Visual symptoms & $12(2.2)$ \\
\hline Other & $75(13.6)$ \\
\hline Patients with prior visits to the ED within 12 months, $n(\%)$ & $84(15.2)$ \\
\hline \multicolumn{2}{|l|}{ Diagnosis at discharge, $n(\%)$} \\
\hline Headache/Headache not-otherwise-specified & $270(48.8)$ \\
\hline Migraine & $238(43.0)$ \\
\hline Tension headache & 27 (4.9) \\
\hline Other primary headache (trigeminal neuralgia, TAC, cough/exercise induced) & $18(3.3)$ \\
\hline \multicolumn{2}{|l|}{ Treatment } \\
\hline Received any medications at triage assessment by nursing, $n(\%)$ & $105(19.0)$ \\
\hline Only received medications at triage, $n(\%)$ & $29(5.2)$ \\
\hline Patients administered medication in ED ordered by ED physician, $n(\%)$ & $524(94.8)$ \\
\hline NSAIDs & $414(74.9)$ \\
\hline Ketorolac IV & $344(62.2)$ \\
\hline Ibuprofen PO & $45(8.1)$ \\
\hline Naproxen PO & $38(6.9)$ \\
\hline Dopamine antagonist (metoclopramide/haloperidol) & $413(74.7)$ \\
\hline Metoclopramide IV & $388(70.2)$ \\
\hline Acetaminophen PO & $210(38.0)$ \\
\hline Antiemetics (dimenhydrinate/ondansetron) & $68(12.3)$ \\
\hline Opioids (morphine/hydromorphone/tramadol) & $64(11.6)$ \\
\hline Local anesthetic (trigger points, nerve blocks, sphenopalatine ganglion blocks) & $10(1.8)$ \\
\hline IV fluids $(\geq 500 \mathrm{ml})$ & $334(60.4)$ \\
\hline Dexamethasone & $113(20.4)$ \\
\hline Other & $88(15.9)$ \\
\hline Diphenhydramine IV/PO & $63(11.4)$ \\
\hline $\mathrm{MgSO}_{4} \mathrm{IV}$ & $9(1.6)$ \\
\hline Received second round medications, $n(\%)$ & $100(18.1)$ \\
\hline \multicolumn{2}{|l|}{ Outcomes and disposition } \\
\hline Pain reassessment documented on chart before discharge, $n(\%)$ & $375(67.8)$ \\
\hline Pain documented by physician as completely relieved, $n(\%)$ & $143(38.1)$ \\
\hline Prescribed medications for home, $n(\%)$ & $81(14.6)$ \\
\hline Formal follow-up requested, $n(\%)$ & $141(25.5)$ \\
\hline Neurology follow-up & $42(7.6)$ \\
\hline Family physician follow-up & $96(17.4)$ \\
\hline Other follow-up & $12(2.2)$ \\
\hline \multicolumn{2}{|l|}{ Lengths of stay (h), mean (SD) } \\
\hline Total length of stay in ED & $5(2.2)$ \\
\hline Time from initial physician assessment to discharge & $2.9(1.9)$ \\
\hline Time from first physician-ordered medication administration to discharge & $2.4(1.9)$ \\
\hline
\end{tabular}


Table 1 (continued)

\begin{tabular}{ll}
\hline Outcomes and disposition & \\
\hline Patient had investigations for headache in the ED, $n(\%)$ & $294(53.2)$ \\
CT head & $195(35.3)$ \\
Lumbar puncture & $22(4.0)$ \\
Bloodwork & $198(35.8)$ \\
ESR & $43(7.8)$ \\
CRP & $35(6.3)$ \\
Patient returned to ED for headache within 7 days, $n(\%)$ & $32(5.8)$ \\
\hline
\end{tabular}

$S D$ standard deviation, $I Q R$ inter quartile range, $E D$ emergency department, $T A C$ trigeminal autonomic cephalalgia, NSAIDs non-steroidal anti-inflammatory drugs, PO Per Os (oral), CT computed tomography, $E S R$ erythrocyte sedimentation rate, $C R P$ C-reactive protein

Table 2 Associations between different variables and the need for second round medications

\begin{tabular}{|c|c|c|c|}
\hline Demographics & $\begin{array}{l}\text { Need for second round } \\
\text { meds } \\
(N=100)\end{array}$ & $\begin{array}{l}\text { No need for second round } \\
\text { meds } \\
(N=453)\end{array}$ & $p$ value* \\
\hline Age in years, mean $(\mathrm{SD})$ & $42.6(17.0)$ & $42.1(16.6)$ & $0.75^{\mathrm{a}}$ \\
\hline Female, $n(\%)$ & $78(78.0)$ & $325(71.7)$ & 0.20 \\
\hline Arrival by ambulance, $n(\%)$ & $25(25.0)$ & $80(17.7)$ & 0.09 \\
\hline Canadian Triage Acuity Scale, median (IQR) & $3(2-3)$ & $3(2-3)$ & $0.02^{\mathrm{b}}$ \\
\hline Triage pain score recorded, $n(\%)$ & $49(49.0)$ & $239(52.8)$ & 0.49 \\
\hline Triage pain score, median (IQR) & $8(7-9)$ & $7(6-9)$ & $0.11^{\mathrm{b}}$ \\
\hline Patients with prior visits to the ED within 12 months, $n$ (\%) & $18(18.0)$ & $66(14.6)$ & 0.39 \\
\hline \multicolumn{4}{|l|}{ Diagnosis at discharge, $n(\%)$} \\
\hline Headache/headache not-otherwise-specified & $39(39.0)$ & $231(51)$ & 0.03 \\
\hline Migraine & $53(53.0)$ & $185(40.8)$ & 0.03 \\
\hline \multicolumn{4}{|l|}{ Treatment } \\
\hline Received any medications at triage assessment by nursing, $n(\%)$ & $15(15.0)$ & $90(19.9)$ & 0.26 \\
\hline NSAIDs & $57(57.0)$ & $328(72.4)$ & 0.002 \\
\hline Ketorolac IV & $41(41.0)$ & $266(58.7)$ & $<0.001$ \\
\hline Ibuprofen PO & $4(4.0)$ & $39(8.6)$ & 0.12 \\
\hline Naproxen PO & $12(12.0)$ & $23(5.1)$ & 0.02 \\
\hline Dopamine antagonist (Metoclopramide/Haloperidol) & $51(51.0)$ & $321(70.9)$ & $<0.001$ \\
\hline Metoclopramide IV & $49(49.0)$ & $299(66)$ & $<0.001$ \\
\hline Acetaminophen PO & $43(43.0)$ & $148(32.7)$ & 0.01 \\
\hline Antiemetics (Dimenhydrinate/Ondansetron) & $23(23.0)$ & $33(7.3)$ & $<0.001$ \\
\hline Opioids (Morphine/Hydromorphone/Tramadol) & $19(19.0)$ & $29(6.4)$ & $<0.001$ \\
\hline IV fluids $(\geq 500 \mathrm{ml})$ & $63(63.0)$ & $255(56.3)$ & 0.03 \\
\hline Dexamethasone & $30(30.0)$ & $83(18.3)$ & 0.009 \\
\hline Diphenhydramine IV/PO & $18(18.0)$ & $45(9.9)$ & 0.21 \\
\hline \multicolumn{4}{|l|}{ Outcomes and disposition } \\
\hline Patient had investigations for headache in the ED, $n(\%)$ & $64(64.0)$ & $230(50.8)$ & 0.02 \\
\hline CT head & $39(39.0)$ & $156(34.4)$ & 0.03 \\
\hline Bloodwork & $52(52.0)$ & $146(32.2)$ & $<0.001$ \\
\hline
\end{tabular}

$S D$ standard deviation, IQR inter quartile range, NSAIDs non-steroidal anti-inflammatory drugs, $P O$ Per Os (oral), CT computed tomography ${ }^{\mathrm{a}} t$ test

${ }^{\mathrm{b}}$ Wilcoxon test

${ }^{*} \chi^{2}$ test unless otherwise noted 
Table 3 Results of the multivariable logistic regression model for need for second round medications

\begin{tabular}{llc}
\hline Variable & Odds ratio (95\% CI) & $p$ value \\
\hline No significant association seen & & \\
Arrival by ambulance & $1.38(0.78-2.43)$ & 0.27 \\
Female & $1.45(0.82-2.57)$ & 0.21 \\
Patients with prior visits to the ED within 12 months & $1.24(0.66-2.33)$ & 0.50 \\
Received any medications at triage assessment by nursing & $1.06(0.54-2.08)$ & 0.86 \\
Patient had investigations for headache in the ED & $1.51(0.92-2.48)$ & 0.10 \\
First round opioids & $1.99(0.98-4.05)$ & 0.06 \\
Associated with decreased second round medications & & \\
First round dopamine antagonist & $0.27(0.14-0.49)$ & 0.001 \\
First round NSAIDs & $0.50(0.30-0.83)$ & \\
Associated with increased second round medication & & 0.001 \\
IV fluids ( $\geq 500$ ml) & $2.79(1.50-5.19)$ & 0.02 \\
First round non-dopamine antagonist antiemetics & $2.21(1.15-4.24)$ & \\
C-statistic (95\% CI) & $0.74(0.68-0.79)$ & \\
\hline
\end{tabular}

CI confidence interval by ambulance, having ED investigations performed, and receiving non-dopamine antagonist antiemetics, IV fluids $\geq 500 \mathrm{ml}$, or diphenhydramine (see Supplementary Table 1). After adjustment through the multivariable regression model (Supplementary Table 2), the independent factors associated with increased length of stay after initial physician assessment were having investigations performed (OR 5.1, 95\% CI 3.1-8.2, $p<0.001)$ and receiving first round non-dopamine antagonist antiemetic medications (OR 2.5, 95\% CI 1.3-4.2, $p<0.001)$. The only factor found to be independently associated with a shorter length of stay after the multivariable regression analysis was receiving first round NSAIDs (OR 0.6, 95\% CI 0.4-0.9, $p=0.03$ ).

\section{Discussion}

\section{Interpretation}

We found that ED primary headache patients administered NSAIDs or dopamine antagonists as initial treatments had significantly reduced need for subsequent medications. Initial treatment with NSAIDs was also associated with shorter lengths of stay. Treatment with first round non-dopamine antagonist antiemetics was associated with significantly higher need for subsequent medications and with longer lengths of stay, highlighting the relative ineffectiveness of these medications in treating primary headache compared to dopamine antagonists. Surprisingly, receiving $\geq 500 \mathrm{~mL}$ of IV fluids was associated with increased rates of second round medication requirement_-possibly because these patients were sicker or more dehydrated. Treatment with opioids showed a trend towards ineffectiveness. Opioid usage rates were lower than in many other studies. However, they were higher than expected given guidelines, such as the American Academy of Neurology's "Choosing Wisely" campaign, recommend that opioids should be used only as a last resort in treating headache pain [21]. Triptans were rarely ordered, perhaps due to ED physicians being less comfortable with their safety profile, but have been shown to be safe and effective medications for migraine [22]. These medications are commonly used as abortive therapies prior to ED presentation [23, 24] and we were unable to capture what medications patients took prior to ED arrival, therefore it is unclear if this contributed to low rates of use. Dihydroergotamine was not ordered in our EDs during the study period, despite it being recommended as a first-line emergent treatment for migraine [14, 25-27]. Many patients received non-contributory blood tests and potentially unnecessary CT imaging; predictably, we found these patients had significantly longer lengths of stay. In low-risk primary headache patients, efforts should be made to successfully treat symptoms with one round of medications and to avoid unnecessary investigations.

\section{Previous literature}

This study demonstrates that NSAIDs and dopamine antagonists are effective first line therapies for treating headache pain in the ED. NSAIDs are well supported in multiple guidelines and systematic reviews as effective first-line treatments for primary headache $[6,14,28,29]$. Their use can also provide benefit when given late in a migraine attack, highlighting their potential for use in emergency settings 
[30]. Dopamine antagonists are also supported by a substantial amount of evidence for the treatment of primary headache $[6,14]$ and their use in ED headache treatment seems to be increasing [31]. While substantial evidence exists for prochlorperazine [18, 32-36], interestingly no clinicians prescribed this medication in our emergency department over the course of the study period. Non-dopamine antagonist antiemetic medications, such as 5-HT3 antagonists (i.e. ondansetron, granisetron), are recommended against by the Canadian Headache Society due to low quality evidence and lack of efficacy [6]. There is little evidence to support the use of either ondansetron or dimenhydrinate for primary headache, and the ineffectiveness of these medications as first line treatments is reflected in our study. IV fluids are often given as a routine part of migraine therapy in emergency settings [31]. Recently published studies have indicated that IV fluids offer no benefit in treating migraine headache pain $[37,38]$. The results of our study support this lack of benefit, as IV fluid boluses were associated with increased need for second round medications. It is also possible that the administration of IV fluids may have delayed other more effective parenteral therapies from being given.

Of note, there are no guidelines spanning the treatment of all primary headaches in the ED or otherwise, due to the significant heterogeneity in the pathogenesis of these disorders. However, many primary headaches that are not formally classified can be identified as migraines on expert review [39, 40]. General practice patterns for non-specific primary headache are typically generated from the literature on migraine treatment, and most therapies recommended for migraine are recommended for other specific subtypes of primary headache and show benefit in non-specific primary headaches [41-45].

\section{Strengths and limitations}

Strengths of this study include the relatively large sample size, the detailed information captured around each visit, the novelty of the study, and the accuracy of the diagnosis of primary headache. The study reviewers analyzed all subsequent visits to our EDs after the index visits and no patients had a secondary cause of headache identified at the study sites. Potential weaknesses of the study include the health records review design, which can be subject to missing data due to poor documentation and misclassification bias. Local practices and medication availability affected the medications used, but there were no algorithms or specific recommendations for headache treatment at our institution. Since our study was conducted at a tertiary care hospital, the results of our study may not be applicable to rural or community emergency departments. We were also unable to evaluate individual reasons for giving IV fluids in patients (i.e. volume status), and therefore it's possible that those who received IV fluids were sicker/ more dehydrated. Despite use of a logistic regression model to control for confounding factors, it's still possible that those who received IV fluids had more severe presentations, which may have ultimately influenced initial treatment choices/investigations in the ED. Furthermore, our study is limited in our abilities to quantify symptom severity; a well-known limitation of triage pain scores is the ceiling effect, wherein we lack the ability to discriminate between levels of pain at upper threshold values. We were also unable to evaluate if patients returned to a different institution for further headache treatments. Finally, we were unable to determine if the associations were related to headache severity, as there was no standardized way of assessing headache severity other than triage pain scores, which were infrequently recorded.

\section{Clinical and research implications}

Emergency physicians should select appropriate first-line medications to optimize the initial therapeutic response in patients being treated for headache. Based on the results of this study, we found the use of parenteral NSAIDs and dopamine antagonists, whether alone or in combination may be associated with decreased need for second round of medication administration. Given the retrospective nature of this study, our results are hypothesis-generating. However, in the absence of any contraindications, it may be reasonable to use both ketorolac IV and metoclopramide IV as initial headache therapy. Our results suggest non-dopamine antagonist antiemetics such as dimenhydrinate and ondansetron should not be used as first-line therapy for primary headache patients. Dopamine antagonists, such as metoclopramide, may be more effective when treating headache-associated nausea and vomiting. Given the lack of evidence for IV fluid use in the treatment of primary headaches in the literature, IV hydration should be reserved for its clinical indications (i.e. dehydration). Avoiding routine use of investigations for low-risk primary headaches may result in decreased lengths of stay. However, these findings will need to be confirmed in future prospective studies.

A potential future study could involve administering patients a combination of effective headache medications at triage and evaluating the impact of this strategy on lengths of stay and the need for subsequent medications to be ordered by an MD. Treatment is generally accepted to be more effective when administered earlier in the headache [27, 46], and receiving medications at triage could potentially be an effective strategy for optimizing ED headache treatment. Future research is needed to assess the impact of using combinations of multiple medications as initial therapy, as most studies have compared single medications only, and this strategy has been shown to be effective in pediatric populations [47]. The specific combination of parenteral ketorolac and 
a dopamine antagonist (such as metoclopramide) should be evaluated in a randomized clinical trial, given the promising results for both classes of medication in this study and others. Evaluating the impact of adding IV fluids to medication regimens should also be explored, as in this study they were associated with less effective initial treatment response.

In summary, this study suggests that for the optimal management of primary headaches in the ED, use of NSAIDs and dopamine antagonists may be associated with higher rates of initial treatment success. Comparatively, non-dopamine antagonist antiemetics and IV fluids may be associated with increased need for subsequent medication treatment. To improve management of ED patients with primary headache, ED physicians should carefully choose initial therapy.

Supplementary Information The online version contains supplementary material available at https://doi.org/10.1007/s43678-021-00173-0.

Acknowledgements The authors would like to acknowledge Li Liu for collecting the data set from the Ottawa Hospital Data Warehouse and Cathy Clement for contributing to proofreading the manuscript.

Author contributions SW, IHS, and JJP conceived the study concept and design. SW, EV, and RL collected the data. MJN organized and analyzed the data. SW, IGS, MJN, and JJP interpreted the data. SW drafted the manuscript and all other authors contributed to the editing of the manuscript for intellectual content. JJP takes responsibility for the paper as a whole.

Sources of funding None to declare. Dr. Perry is supported by a MidCareer Grant from the Heart and Stroke Foundation of Ontario.

\section{Declarations}

Conflict of interest None to declare.

\section{References}

1. Headache Classification Committee of the International Headache Society (IHS). The international classification of headache disorders, 3rd edition. Cephalalgia. 2018;38(1):1-211. https://doi.org/ 10.1177/0333102417738202.

2. Cerbo R, Villani V, Bruti G, Di Stani F, Mostardini C. Primary headache in emergency department: prevalence, clinical features and therapeutical approach. J Headache Pain. 2005;6(4):287-9. https://doi.org/10.1007/s10194-005-0210-1.

3. Barton CW. Evaluation and treatment of headache patients in the emergency department: a survey. Headache. 1994;34(2):91-4. https://doi.org/10.1111/j.1526-4610.1994.hed3402091.x.

4. Vinson DR. Treatment patterns of isolated benign headache in US emergency departments. Ann Emerg Med. 2002;39(3):215-22. https://doi.org/10.1067/mem.2002.121400.

5. Sahai-Srivastava S, Desai P, Zheng L. Analysis of headache management in a busy emergency room in the United States. Headache. 2008;48(6):931-8. https://doi.org/10.1111/j.1526-4610. 2008.01156.x

6. Orr SL, Aubé M, Becker WJ, et al. Canadian Headache Society systematic review and recommendations on the treatment of migraine pain in emergency settings. Cephalalgia Int J Headache. 2015;35(3):271-84. https://doi.org/10.1177/0333102414535997.

7. Pryse-Phillips W, Findlay H, Tugwell P, Edmeads J, Murray TJ, Nelson RF. A Canadian population survey on the clinical, epidemiologic and societal impact of migraine and tension-type headache. Can J Neurol Sci J Can Sci Neurol. 1992;19(3):333-9.

8. Munakata J, Hazard E, Serrano D, et al. Economic burden of transformed migraine: results from the American Migraine Prevalence and Prevention (AMPP) Study. Headache. 2009;49(4):498 508. https://doi.org/10.1111/j.1526-4610.2009.01369.x.

9. Godwin SA, Cherkas DS, Panagos PD, Shih RD, Byyny R, Wolf SJ. Clinical policy: critical issues in the evaluation and management of adult patients presenting to the emergency department with acute headache (executive summary): approved by the ACEP Board of Directors June 26, 2019 clinical policy endorsed by the Emergency Nurses Association (July 31, 2019). Ann Emerg Med. 2019;74(4):578-9. https://doi.org/10.1016/S0196-0644(19) 31168-0.

10. Becker WJ, Findlay T, Moga C, Scott NA, Harstall C, Taenzer P. Guideline for primary care management of headache in adults. Can Fam Phys. 2015;61(8):670-9.

11. Saguil A, Lax JW. Acute migraine treatment in emergency settings. Am Fam Phys. 2014;89(9):742-4.

12. Nijjar SS, Pink L, Gordon AS. Examination of migraine management in emergency departments. Pain Res Manag J Can Pain Soc. 2011;16(3):183-6.

13. Naeem F, Schramm C, Friedman BW. Emergent management of primary headache: a review of current literature. Curr Opin Neurol. 2018;31(3):286-90. https://doi.org/10.1097/WCO.00000 00000000547.

14. Marmura MJ, Silberstein SD, Schwedt TJ. The acute treatment of migraine in adults: the American Headache Society evidence assessment of migraine pharmacotherapies. Headache. 2015;55(1):3-20. https://doi.org/10.1111/head.12499.

15. Colman I, Rothney A, Wright SC, Zilkalns B, Rowe BH. Use of narcotic analgesics in the emergency department treatment of migraine headache. Neurology. 2004;62(10):1695-700. https:// doi.org/10.1212/01.wnl.0000127304.91605.ba.

16. Wasay M, Zaki KS, Khan SU, Rehmani R. Narcotic analgesics for acute migraine in the emergency room: are we meeting Headache Societies' guidelines? J Headache Pain. 2006;7(6):413-5. https:// doi.org/10.1007/s10194-006-0338-7.

17. Tornabene SV, Deutsch R, Davis DP, Chan TC, Vilke GM. Evaluating the use and timing of opioids for the treatment of migraine headaches in the emergency department. J Emerg Med. 2009;36(4):333-7. https://doi.org/10.1016/j.jemermed.2007.07. 068.

18. Friedman BW, Irizarry E, Solorzano C, et al. Randomized study of IV prochlorperazine plus diphenhydramine vs IV hydromorphone for migraine. Neurology. 2017;89(20):2075-82. https://doi.org/10. 1212/WNL.0000000000004642.

19. Sheridan DC, Meckler GD. Inpatient pediatric migraine treatment: does choice of abortive therapy affect length of stay? J Pediatr. 2016;179:211-5. https://doi.org/10.1016/j.jpeds.2016.08.050.

20. Miller J, Koons L, Longyhore D (2020) Opioid free treatment algorithm for ED headache management: Effect on revisit rate. Am J Emerg Med 38(1):28-32. https://doi.org/10.1016/j.ajem. 2019.03.053*

21. Langer-Gould AM, Anderson WE, Armstrong MJ, et al. The American Academy of Neurology's top five choosing wisely recommendations. Neurology. 2013;81(11):1004-11. https://doi.org/ 10.1212/WNL.0b013e31828aab14.

22. Derry CJ, Derry S, Moore RA. Sumatriptan (all routes of administration) for acute migraine attacks in adults-overview of Cochrane reviews. Cochrane Database Syst Rev. 2014. https:// doi.org/10.1002/14651858.CD009108.pub2. 
23. Lipton RB, Bigal ME, Diamond M, et al. Migraine prevalence, disease burden, and the need for preventive therapy. Neurology. 2007;68(5):343-9. https://doi.org/10.1212/01.wnl.0000252808. 97649.21.

24. Diamond S, Bigal ME, Silberstein S, Loder E, Reed M, Lipton RB. Patterns of diagnosis and acute and preventive treatment for migraine in the United States: results from the American Migraine Prevalence and Prevention study. Headache. 2007;47(3):355-63. https://doi.org/10.1111/j.1526-4610.2006.00631.x.

25. Kelley NE, Tepper DE. Rescue therapy for acute migraine, part 1: triptans, dihydroergotamine, and magnesium. Headache. 2012;52(1):114-28. https://doi.org/10.1111/j.1526-4610.2011. 02062.x

26. Worthington I, Pringsheim T, Gawel MJ, et al. Canadian Headache Society Guideline: acute drug therapy for migraine headache. Can J Neurol Sci J Can Sci Neurol. 2013;40(5 Suppl 3):S1-80.

27. Pringsheim T, Davenport WJ, Marmura MJ, Schwedt TJ, Silberstein S. How to apply the AHS evidence assessment of the acute treatment of migraine in adults to your patient with migraine. Headache. 2016;56(7):1194-200. https://doi.org/10.1111/head. 12870.

28. Rabbie R, Derry S, Moore RA. Ibuprofen with or without an antiemetic for acute migraine headaches in adults. Cochrane Database Syst Rev. 2013. https://doi.org/10.1002/14651858.CD008 039.pub3.

29. Taggart E, Doran S, Kokotillo A, Campbell S, Villa-Roel C, Rowe $\mathrm{BH}$. Ketorolac in the treatment of acute migraine: a systematic review. Headache. 2013;53(2):277-87. https://doi.org/10.1111/ head.12009.

30. Kelley NE, Tepper DE. Rescue therapy for acute migraine, part 3: opioids, NSAIDs, steroids, and post-discharge medications. Headache. 2012;52(3):467-82. https://doi.org/10.1111/j.15264610.2012.02097.x.

31. Ruzek M, Richman P, Eskin B, Allegra JR. ED treatment of migraine patients has changed. Am J Emerg Med. 2019;37(6):1069-72. https://doi.org/10.1016/j.ajem.2018.08.051.

32. Coppola M, Yealy DM, Leibold RA. Randomized, placebo-controlled evaluation of prochlorperazine versus metoclopramide for emergency department treatment of migraine headache. Ann Emerg Med. 1995;26(5):541-6. https://doi.org/10.1016/s01960644(95)70001-3.

33. Jones J, Pack S, Chun E. Intramuscular prochlorperazine versus metoclopramide as single-agent therapy for the treatment of acute migraine headache. Am J Emerg Med. 1996;14(3):262-4. https:// doi.org/10.1016/S0735-6757(96)90171-0.

34. Zitek T, Gates M, Pitotti C, et al. A comparison of headache treatment in the emergency department: prochlorperazine versus ketamine. Ann Emerg Med. 2018;71(3):369-377.e1. https://doi.org/10. 1016/j.annemergmed.2017.08.063.

35. Seim MB, March JA, Dunn KA. Intravenous ketorolac vs intravenous prochlorperazine for the treatment of migraine headaches. Acad Emerg Med Off J Soc Acad Emerg Med. 1998;5(6):573-6. https://doi.org/10.1111/j.1553-2712.1998.tb02463.x.
36. Golikhatir I, Cheraghmakani H, Bozorgi F, Jahanian F, Sazgar $\mathrm{M}$, Montazer SH. The efficacy and safety of prochlorperazine in patients with acute migraine: a systematic review and metaanalysis. Headache. 2019;59(5):682-700. https://doi.org/10.1111/ head.13527.

37. Zitek T, Sigal T, Sun G, Manuel CM, Tran K. I-FiBH trial: intravenous fluids in benign headaches - a randomised, single-blinded clinical trial. Emerg Med J. 2020;37(8):469-73. https://doi.org/ 10.1136/emermed-2019-209389.

38. Jones CW, Remboski LB, Freeze B, Braz VA, Gaughan JP, McLean SA. Intravenous fluid for the treatment of emergency department patients with migraine headache: a randomized controlled trial. Ann Emerg Med. 2019;73(2):150-6. https://doi.org/ 10.1016/j.annemergmed.2018.09.004

39. Maizels M. Headache evaluation and treatment by primary care physicians in an emergency department in the era of triptans. Arch Intern Med. 2001;161(16):1969-73. https://doi.org/10.1001/archi nte.161.16.1969.

40. Blumenthal HJ, Weisz MA, Kelly KM, Mayer RL, Blonsky J. Treatment of primary headache in the emergency department. Headache. 2003;43(10):1026-31. https://doi.org/10.1046/j.15264610.2003.03202.x.

41. Friedman BW, Grosberg BM. Diagnosis and management of the primary headache disorders in the emergency department setting. Emerg Med Clin North Am. 2009;27(1):71. https://doi.org/10. 1016/j.emc.2008.09.005.

42. Trainor A, Miner J. Pain treatment and relief among patients with primary headache subtypes in the ED. Am J Emerg Med. 2008;26(9):1029-34. https://doi.org/10.1016/j.ajem.2007.12.008.

43. Miner JR, Smith SW, Moore J, Biros M. Sumatriptan for the treatment of undifferentiated primary headaches in the ED. Am J Emerg Med. 2007;25(1):60-4. https://doi.org/10.1016/j.ajem. 2006.06.004.

44. Friedman BW, Adewunmi V, Campbell C, et al. A randomized trial of intravenous ketorolac versus intravenous metoclopramide plus diphenhydramine for tension-type and all nonmigraine, noncluster recurrent headaches. Ann Emerg Med. 2013;62(4):311318.e4. https://doi.org/10.1016/j.annemergmed.2013.03.017.

45. Cicek M, Karcioglu O, Parlak I, et al. Prospective, randomised, double blind, controlled comparison of metoclopramide and pethidine in the emergency treatment of acute primary vascular and tension type headache episodes. Emerg Med J. 2004;21(3):323-6. https://doi.org/10.1136/emj.2002.000356.

46. Marissa Lagman-Bartolome A, Lay C. The traffic light of headache: simplifying acute migraine management for physicians and patients using the Canadian Headache Society guidelines. Headache. 2019;59(2):250-2. https://doi.org/10.1111/head.13428.

47. Leung S, Bulloch B, Young C, Yonker M, Hostetler M. Effectiveness of standardized combination therapy for migraine treatment in the pediatric emergency department. Headache. 2013;53(3):491-197. https://doi.org/10.1111/head.12042. 